\title{
Examination Text Structure as an Indicator of Examination Task Type and Complexity (On the Basis of GCSE English Language Unit 1 Section A Reading)
}

\author{
Yuliya N. Gorelova \\ PhD, Associate Professor, Kazan Federal University, Institute of Management, \\ Economics and Finance Kazan, Russian Federation \\ gorelovajuliya@gmail.com
}

Ekaterina 0. Zalyaeva

PhD, Associate Professor, Kazan Federal University, Institute of Management, Economics and Finance, Kazan, Russian Federation erunaz@mail.ru

\section{Dilyana D. Sungatullina}

Assistant Professor, Kazan Federal University, Institute of Management, Economics and Finance, Kazan, Russian Federation

Doi:10.5901/mjss.2015.v6n3s2p414

dilyana87@mail.ru

\begin{abstract}
This paper investigates expository and narrative structures of examination texts for reading purposes implemented in General Certificate of Secondary Education (GCSE) English Language Unit 1 Section A Reading). 48 texts (taken from real exam papers GCSE English Language Foundation and Higher, developed and used by Assessment and Qualifications Alliance (AQA) in 2011-2013) constituted the material of the study. The aim of the research is to define the organizational structure of the examination texts in order to help the candidates cope with tasks successfully. Such research methods as semantic analysis, qualitative and quantitative methods, descriptive statistics have led to the results, which can be applied by both testmakers and candidates. Thorough investigation of their structural features, content and keywords as well as tasks accompanying the texts revealed that text structure has a direct impact on the type of tasks and questions proposed to a candidate in exam likewise their complexity. When developing examination tasks and questions test-makers should take into consideration peculiarities of each text structure and establish methodological guidelines for the potential candidates to pass the exam swimmingly.
\end{abstract}

Keywords: text structure, expository texts, narrative texts, examination discourse, GCSE.

\section{Introduction}

Global forces modifying today's reality by means of social and academic mobility, internationalization, integration into the world community induce nations to maintain and improve education quality standards. In this context the development of students' academic achievements assessment system deserves close attention. The candidate's (a person who is passing exam or takes a test) success in exam might be determined by the amount of knowledge, skills, abilities and experience he/she possesses at a critical period of education process. However, the level of student's competence in a discipline is not the only factor affecting his/her exam mark. The other point worth of consideration is the exam design, i.e. evaluation of exam's usefulness, identification of its objectives, specification development, approbation, validation, handbooks issue and staff training (Hughes, 2003:58, Bachman \& Palmer, 1996). Thus, the aim of this paper is to identify the main structural patterns occurring in examination texts within GCSE, their typical features and the basic task types accompanying them.

GCSE is an academic qualification awarded in a specified subject and generally taken by secondary education pupils in England, Wales and Northern Ireland. The exam level (Foundation - lower level, Higher - advanced level) affects the marks that candidates get for their performance in exam as well as the institution they will continue their education at. This paper will specialize at the analysis of texts, employed as the examination material in General 
Certificate of Secondary Education (GCSE) English Language Unit 1 Section A Reading.

Reading assessment is a challenge for examiners since there are no clear boundaries between what can be measured and what cannot. Text interpretation is a specific activity, which is dependent on the readers' backgrounds, experiences and interests (Alderson, 2000:95). Nevertheless, the explicit and implicit information comprehension, information synthesis, word knowledge and inference making are those 'linguistic skills' which can undergo testing in exam. Thus, we will look upon the texts implemented in GCSE English Language Unit 1 Section A Reading from the point of view of their textual structures as well as the task type accompanying them, i.e. linguistic skills which will be tested in each case.

The examiners' reports on understanding and producing non-fiction texts for both Foundation and Higher levels show that the candidates struggle with using the quotation to support what has been understood rather than paraphrasing it and using as a part of their statement on the given topic. According to the reports, less successful candidates fail to compare presentational features of the two texts and make the use of words, phrases or language features the initial focus of their comparison.

The candidates' complete success on the exam depends a lot on the tutors' approach during preparation for its taking. The main aim is to get communicative competence that is in its turn can't be achieved without several components, in particular: proper guidance, facilitation, motivation and collaboration (Zalyaeva and Solodkova, 2014: 1041). Motivation is also an indispensable factor, which usually encourages the student to certain activities with the help of external and intrapersonal factors (Galishnikova, 2014: 1139).

\section{Methods and Materials}

Material for the research is taken from "GCSE English Language Unit 1 Section A Reading" and covers 48 texts taken from real exam papers GCSE English Language Foundation and Higher, developed and used by Assessment and Qualifications Alliance (AQA) in 2011-2013.

The authors utilized textual observations for identifying and classifying the texts, using their formal characteristics.

The prevailing research instrument is the semantic analysis performed by the authors, which is aimed at identifying key words, which might be of great help for the candidate to define the appropriate text structural pattern of the text they are working with. We proceed from the assumption that the theoretical study performed by Goddard (1998) will form the basis of our investigation.

The research paper uses qualitative methods for description and interpretation of the various text structural patterns used in reading passages; quantitative methods for calculating the amount of narrative and expository texts in each exam set, the percentage of the most popular text structures at the two levels. Descriptive statistics was applied for summarizing data to make them more comprehensible.

The described methods are a constituent part of any semantic and structural analysis and appear to be of practical and reasonable usage within the GCSE's textual patterns investigation.

\section{Theoretical Review}

\subsection{Text Structures in terms of examination discourse}

Examination discourse is a situation of direct and indirect interaction between participants (a candidate, an examiner, an expert, a developer of exam materials), which exists in texts of written and oral communication. Within the scope of a language test, examination discourse enables the candidate to illustrate his/her language ability (reading comprehension, listening speaking and writing) as well as language knowledge (grammar, vocabulary, rules of language usage). On the other hand, examination discourse provides quantitative assessment of candidate's language skills and language knowledge.

Examination text is a specially designed textual material, which satisfies the goals and objectives of examination discourse. It's generally accompanied by tasks, instructions and questions facilitating candidate's language abilities determination. In this sense a great importance is attached to the text structure. The concept of "text structure" refers to the organizational features of a text that can serve as a frame or pattern guiding reader in the reading comprehension process (Englert \& Thomas, 1987; Seidenberg, 1986). There's no doubt that semantic and syntactic hierarchy of a text enables the reader to build a sequence of visual images that express the content of the text (Denis, 1982:540-545), which consequently leads to the comprehension of textual information as well as its memorization (Dickson et al., 1995). Whereas in the context of examination discourse text structure facilitates the candidate in the process of relevant 
information search, logical relations establishment and examination tasks accomplishment. Moreover, numerous studies (Dickson, 1995; Kintsch \& Yarborough, 1982; Meyer \& Freedle, 1984; Rossi, 1990; Winograd, 1983) argue that texts with a clear structural organization have a positive impact on the after-text tasks effective accomplishment, particularly those that are aimed at identifying the main idea of the text.

Traditional text structures classification in the English language includes the following types: narrative, descriptive, argumentative and expository. The analysis of 48 examination texts exposed that descriptive and argumentative text structures are not included into the framework of GCSE English Language Unit 1 Section A Reading, since only nonfiction texts are employed as examination material in this assessment procedure.

Any non-fiction text consists of four interrelated and interdependent sectors: cognitive (reflects elements of specific scientific knowledge), linguistic (language serves as a means of knowledge, concept and values system expression), social (localized in a particular society) and cultural (being a part of a certain culture it reflects cultural values of a particular community) (Gorelova, 2014: 669). A non-fiction text also possesses a distinct structural organization due to the fact that its elements are organized into certain thematic areas forming a macrostructure of the text (Saunders-Smith, 2009:1). Advertising or information bulletin, textbooks, magazine article, travel notes, biography or autobiography usually refer to non-fiction texts. Thus, the basis of our scientific research will be constituted by expository and narrative texts.

\subsection{Narrative and Expository Text Structures}

Narrative presents events, phenomena, actions and feelings in a time sequence (Graesser et al, 1991; Dickson et al., 1995). The content of narrative texts, as well as the actions of the main characters relate to the material world in which the reader exists (Graesser et al., 1991:173). The main objective of this text type is to make the reader draw conclusions on the basis of implicitly stated information of the text. Components of the explicit information (exposition - conflict rising action - climax - falling action - resolution) in the narrative text form a chain, each link of which promotes content comprehension and recall.

Expository texts absolutely differ from narrative ones in structure, content and purpose. The main objective of expository texts is to transfer knowledge, information, facts, to explain the characteristics of specific phenomena. Software documentation, educational texts, essays and newspaper articles, textbooks are the typical examples of expository texts. They are widely implemented as examination material in such assessment systems as International Language Testing System (IELTS), Test of English as a Foreign Language (TOEFL), GCSE English Language, American College Testing (ACT) Reading.

The organizational structure of expository text is characterized by a compound relations between its components and has a broader range of organizational patterns, in contrast to the narrative text, the structure of which has a linear orientation. Common expository text structures involve classification/sequence, description, causation, problem solution, comparison - contrast types (Meyer \& Freedle, 1984:122-123):

Table 1: Expository Text Structure Patterns

\begin{tabular}{|c|c|c|}
\hline № Text Structure & Features & Key words \\
\hline 1 Collection/Sequence & $\begin{array}{l}\text { The basic information units are located in a specific sequence } \\
\text { according to the hierarchy of meanings (e.g.in chronological } \\
\text { order of events or according to family ties of people that are } \\
\text { mentioned in the message). }\end{array}$ & $\begin{array}{l}\text { The following, then, in addition, another, } \\
\text { well, furthermore, finally }\end{array}$ \\
\hline 2 Description & $\begin{array}{l}\text { A more structured text type where propositions are grouped } \\
\text { according to the type of relations between them: usually one } \\
\text { element is subordinate to the other. This structure type is } \\
\text { characterized by the abundance of supporting information. }\end{array}$ & $\begin{array}{l}\text { First, next, second until, third, while, last, } \\
\text { soon, then, after, at that time, now, during, } \\
\text { immediately }\end{array}$ \\
\hline 3 Causation & $\begin{array}{l}\text { It combines collection and description with the only difference } \\
\text { that all the elements are grouped according to the cause-and- } \\
\text { effect relationships between them. }\end{array}$ & $\begin{array}{l}\text { For this reason, thus, in order to, as a result, } \\
\text { because, consequently, so that, on account } \\
\text { of, therefore, accordingly }\end{array}$ \\
\hline 4 Problem-Solution & $\begin{array}{l}\text { It preserves the organizational components of causation type } \\
\text { and is characterized by the requirement that "at least one aspect } \\
\text { of the solution matches in content and stops an antecedent of } \\
\text { the problem". }\end{array}$ & \\
\hline 5 Comparison-Contrast & $\begin{array}{l}\text { This type of structure combines elements on the basis of their } \\
\text { similarities and differences. }\end{array}$ & $\begin{array}{l}\text { However, even though, but, on the contrary, } \\
\text { yet, otherwise, despite, in comparison, still, } \\
\text { on the other hand }\end{array}$ \\
\hline
\end{tabular}


Another schema is presented in the paper by Weaver and Kintsch (Weaver \& Kintsch, 1991:238-239). Researchers identified three types of structural relations in expository texts: 1) general-particular (identification, definition, classification, illustration); 2) object - object (comparison/contrast); object - part (structural analysis, functional analysis, causal analysis). Fundamental differences between the classifications have not been found since it is the amount of information (excess and deficiency) and type of relations between propositions in the text which underlies both schemata. However, our study will apply to the theory proposed by B. Meyer \& P. Freedle, since it perfectly reflects the text structure impact on the process of textual information perception, comprehension and recall.

Propositions of expository text conveying the main idea of the text are interrelated due to the argument overlap and consequently organize a hierarchical text base. In other words, hierarchical relations between macro- and micropropositions are the basis of this text type organization (Weaver \& Kintsch, 1991:233-234). The more complex is the connection between propositions - the more effective is textual information recall process. The studies show (Meyer \& Freedle, 1984; Sanders \& Norman, 2000; Spooren, Mulder \& Hoeken, 1998; Wylie \& McGuiness, 2004) that top-level structures of expository text (such as causation, comparison - contrast, problem - solution) facilitate candidates' performance especially in those tasks that are aimed at global comprehension assessment. Whereas the usage of lowlevel structures such as collection/sequence, description is more appropriate in the learning process (McNamara \& Kintsch et al., 1996).

Holsgrove (2011:62-63) underlines that the effectiveness of expository text comprehension and recall depends not only on the text structure, but also on its authenticity. The use of 'artificial' texts, which are based on only one type of text structure with absolute exclusion of other structures, cannot be used as a valid examination material due to its deficiency and inadequacy. Consequently, any expository text employed in examination discourse should be characterized by a sufficient level of complexity and length and include text structures of various types (Ismagilova et al., 2014:1098).

The research on narrative and expository texts revealed the fact that the latter ones are more difficult for comprehension. The difference between two text structures lies in the fact that the interaction of the candidate with expository text implies not only pragmatic and linguistic maturity of the candidate, but also his/her knowledge of these text type organizational features. The researchers (Meyer, Brandt, \& Bluth, 1980; Meyer \& Rice, 1982) claim that the lack of skills in expository text structure recognition prevents the candidate from processing textual information. Candidates regard a text not as a single entity but as a set of ideas, which are randomly related to each other. Whereas text structure awareness, knowledge of text structure facilitates coherent mental projection of the text in the candidate's mind (Meyer et al., 1980; Taylor \& Samuels, 1983), which is the basis for the main idea comprehension process.

\section{Results}

The investigation of 48 examination texts taken from GCSE English Language Foundation \& Higher Unit 1 Section A Reading has revealed that each examination paper set contains one narrative and two expository texts:

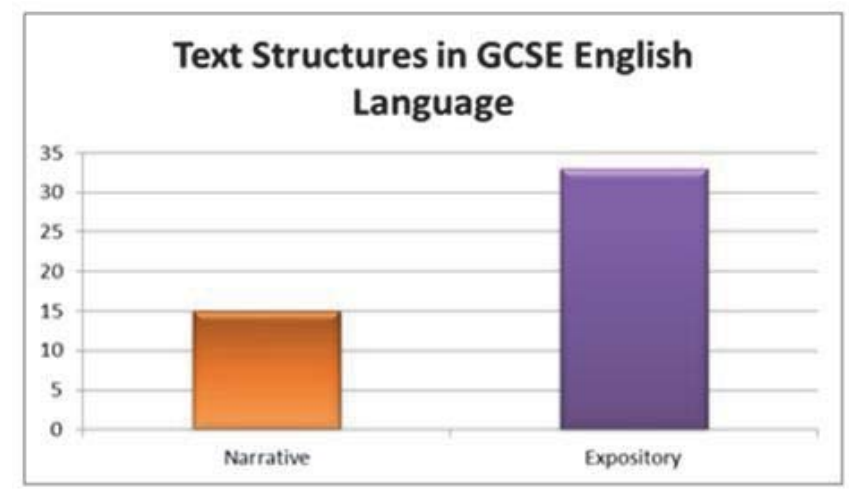

Chart 1: Text Structures of examination material in GCSE English Language Reading Section

Expository text structures analysis exposed that description was the most popular text structure at the Foundation Level, whereas description, causation and comparison - contrast were equally widespread at the Higher Level: 


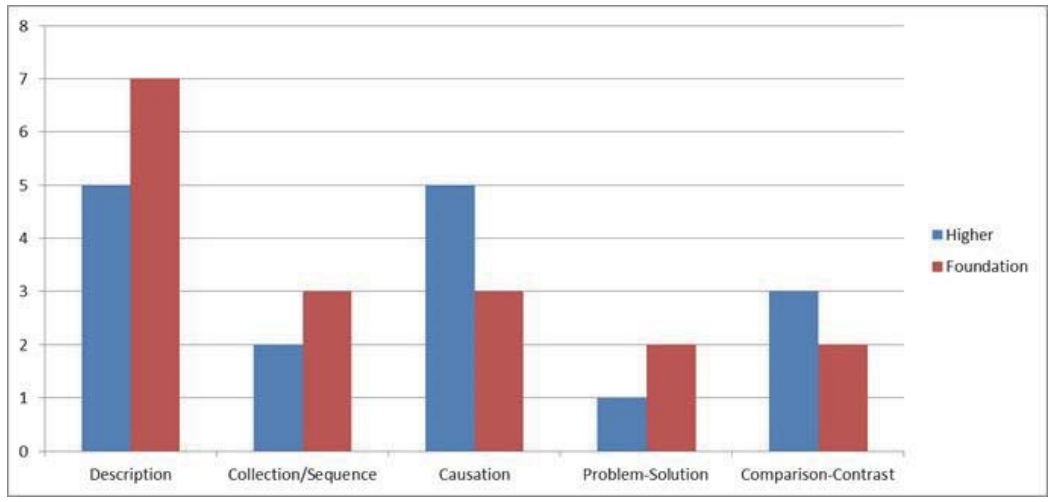

Chart 2: Expository text structures employed in GCSE English Language Reading Section

Expository texts implemented at the Foundation level belong to low-level structures (Description, Collection/Sequence), as opposed to the texts of the Higher level, that are characterized by complex relations within the hierarchy of textual propositions (Causation, Comparison - Contrasting, Problem - Solution). The usage of Problem - Solution structure is relatively rare, owing to the fact that this structure type is widespread in the scientific papers (their main objective is to define the problem, predict the most probable solutions and choose the most effective way of its elimination), which makes it difficult to establish the links between the parts of the text and in this way prevents candidates from global comprehension of the text.

\section{Discussions}

A thorough investigation of examination texts structural organization as well as their tasks and questions has revealed that this is the structure of the text that determines the task type and the degree of its complexity for the candidate.

Narattive texts reading comprehension in GCSE English Language Unit 1 Section A Reading presupposes that the candidate possesses certain language skills and abilities as well as knowledge that will facilitate the process of implicit information perception along with denotative and communicative content analysis. Compare:

Now read Source 2, from Race to the Pole. In this extract, Ben Fogle describes the training he and his colleague James went through before undertaking a race across Antarctica.

What do you understand about the difficulties they faced in training for the race? Remember to show your understanding by explaining in your own words, support your ideas with the text. (8 marks) (GCSE English Language. Unit 01 (Foundation): Question Paper. November, 2013)

Candidates also need to demonstrate general comprehension of an abstract as well as significant supporting information; support their point of view by means of appropriate and detailed references from the text; use the text as a primary source of information; state problems faced by the main characters. For example, the task, accompanying nonfiction text "Race to the Pole" in GCSE English Language Foundation level exam paper from November 2013, is aimed at measurement the candidate's ability to understand the feelings and difficulties experienced by the main characters of an abstract in their attempt to conquer the Pole. This can be done by the candidate's skills of context clues identification (Gorelova et al., 2015:553): 'the freezing air burnt my throat', 'Unzipping the door with my frozen hands had been like buttoning a shirt with an oven glove', 'the stove was too cold to ignite' (GCSE English Language. Unit 01 (Foundation): Question Paper. November, 2013). The specification for GCSE English Language exam indicates that correct decoding of these clues can facilitate the author's message comprehension: the power of cold can be demolishing ('the cold caused physical pain, interfered with the most basic actions, knocked out of service a machine that would help people stay warm').

The research on expository texts' examination questions and tasks in GCSE English Language Reading Section has defined the functional purpose of these texts within the framework of examination discourse. Regardless of the exam complexity (Higher or Foundation levels) expository texts serve as a means for obtaining reliable information on the candidates' main idea comprehension ability as well as their ability to find relations between textual propositions within the process of coherent textual model creation; their language proficiency level and language speech norms knowledge as well: 
What do you learn from Elisabeth Hyde's article about where she has been and what she has been doing? (general comprehension)

Explain how the headline? Sub-headline and picture are effective and how they link with the text? (GCSE English Language. Unit 01 (Higher): Question Paper. January, 2011) (ability to work with hypertext, and graphic signals; the ability to perceive them as supporting elements in the process of the main idea comprehension).

Now read Source 3, an extract from an advice leaflet called Getting on with your Teenager and answer the question below:

How does the writer use language:

- to inform the reader about teenagers and

- to advise parents and carers? (GCSE English Language. Unit 01 (Foundation): Question Paper. January, 2011)

(lexical content analysis of the text in terms of its efficiency to perform the function of informing and advising)

\section{Conclusion}

Research and comparative analysis of the exam texts in GCSE English Language Unit 1 Section A Reading revealed that narrative and expository text structures are the major structures employed within the assessment system under discussion. When working with narrative texts, the candidate is obliged to demonstrate the degree of the main idea comprehension as well as his ability to recognize the hidden signals of the text (i.e. implicitly-stated information). In addition to this, it's essential for the candidate to interpret those signals correctly and indicate the main problem of the text as well as the author's message. In contrast to the narrative texts, expository ones serve as a means of illustration the candidate's degree of the main idea comprehension along with the level of language proficiency.

\section{References}

Alderson J. Ch. (2000). Assessing Reading. Cambridge University Press. 398p.

Bachman, L.F., Palmer A.S. (1996). Language Testing in Practice: Designing and Developing Useful Language Tests. Oxford University Press. 377p.

Denis M. (1982). Imaging while reading text: A study of individual differences, in Memory and Cognition, 10, (6): pp. 540-545.

Dickson S. V. et al. (1995). Text Organization and Its Relation to Reading Comprehension: A Synthesis of the Research. University of Oregon. 60 p.

Englert, C. S., \& Thomas, C. C. (1987). Sensitivity to text structure in reading and writing: A comparison between learning disabled and non-learning disabled students, in Learning Disability Quarterly, 10: pp. 93-105.

Galishnikova Elena M. (2014) Language learning motivation: A look at the additional program, in Procedia - Social and Behavioral Sciences, 152: pp. 1137-1142.

GCSE English Language. Unit 01 - Understanding and Producing Non-Fiction Texts (Higher): Question Paper. AQA, January, 2011. 24 p.

Goddard C. (1998) Semantic Analysis: A Practical Introduction. Oxford University Press. 411 p.

Gorelova Y.N., Zalyaeva E.O., Sungatullina D.D. (2015). Semantic Context Clues in Expository Texts for TOEFL iBT Reading Section Preparation, in Mediterranean Journal of Social Sciences, 6, (1): pp. 551-559.

Gorelova Yuliya N. (2014) Advertising language as a means of forming students' cross-cultural competence, in Procedia - Social and Behavioral Sciences, 152: pp. $668-672$.

Graesser A., Golding J.M., Long D.L. (1991). Narrative representation and comprehension, in Handbook of Reading Research, 2: pp 171-205.

Holsgrove J.V. (2011). Structure Strategy Use in Children's Comprehension of Expository Texts. Edith Cowan University. 237 p.

Hughes A. (2003). Testing for Language Teachers. Cambridge University Press. 251p.

Ismagilova Liliya R., Polyakova Oksana V. (2014). The problem of the syllabus design within the competence approach based on the course "English for Master Degree Students in Economics (advanced level)", in Procedia - Social and Behavioral Sciences, 152: pp. $1095-1100$

McNamara, D.S., Kintsch, E., Songer, N.B., \& Kintsch, W. (1996). Are good texts always better? Interactions of text coherence, prior knowledge, and levels of understanding in learning from text, in Cognition and Instruction, 14: pp. 1-43.

Meyer B. \& Freedle R. (1984). Effects of Discourse Type on Recall, in American Educational Research Journal, 21, (1): pp. 121-143.

Meyer B. \& Ray N. R. (2011). Individual differences in children's knowledge of expository text structures: A review of literature, in International Electronic Journal of Elementary Education, 2011, 4, (1): pp. 67-82.

Saunders-Smith G. (2009). Non-Fiction Text Structures for Better Comprehension and Response. Maupin House Publishing. 122 p.

Seidenberg, P.L.(1986). Getting the gist: Relating text processing research to reading and writing instruction for learning disabled 
secondary students (Document No...5). Long Island University Transition Project. 15 p.

Weaver, Ch. A., III, \& Kintsch, W. (1991). Expository text, in Handbook of Reading Research, 2: pp. 230-244.

Zalyaeva E.O., Solodkova I.M. (2014) Teacher-students Collaboration: Institute of Economics and Finance Kazan Federal University Approach, in Procedia - Social and Behavioral Sciences, 152: pp. 1039-1044.

GCSE Past Papers and Examiner's Report. [Online] Available: http://www.aqa.org.uk/subjects/english/gcse/english-language-4705/pastpapers-and-mark-schemes

GCSE Specification English Language 4705. [Online] Available: http://filestore.aqa.org.uk/subjects/AQA-4705-W-SP-14.PDF (February, 10, 2015)

GCSE English Language. Unit 01 - Understanding and Producing Non-Fiction Texts (Foundation): Mark Scheme. AQA. November, 2013. [Online] Available: http://filestore.aqa.org.uk/subjects/AQA-ENG1F-MS-NOV13.PDF (February, 10, 2015).

GCSE English Language. Unit 01 - Understanding and Producing Non-Fiction Texts (Foundation): Question Paper. AQA. January, 2011. [Online] Available: http://www.bitterneparkschool.org.uk/wp-content/uploads/2014/03/AQA-ENG1F-W-QP-JAN11.pdf (February, 10, 2015).

GCSE English Language. Unit 01 - Understanding and Producing Non-Fiction Texts (Foundation): Question Paper. AQA. November, 2013 [Online] Available: http://filestore.aqa.org.uk/subjects/AQA-ENG1F-QP-NOV13.PDF (February, 10, 2015) 